\title{
PROBABLE RANGE EXTENSION OF THE OLIVE-BACKED POCKET MOUSE IN SASKATCHEWAN
}

\author{
by HUGH C. SMITH*
}

The analysis of skeletal remains found in the pellets of hawks and owls has frequently been used to determine the foods of these birds. A by-product of such analysis is the occasional discovery of an animal that is new to an area.

While examining mammalian skeletal material recovered from pellets of Great Horned Owls, several mandibles of the Olive-backed Pocket Mouse (Perognathus fasciatus) were found. The pellets were collected from owl nest sites by Dr. C. S. Houston during May, 1969 and 1971. Identification was done by comparing the teeth with known specimens from the mammal collection in the Provincial Museum of Alberta and confirmed by Dr. John E. Storer, Curator of Earth Science, Provincial Museum of Alberta.

The nests were located in the vicinity of the following places (numbers refer to sites marked on map): (1) Bladworth, (2) Junction Highways 2 and 5, 40 miles east of Saskatoon, (3) 3 miles southwest of Birch Hills, (4) Blackstrap Reservoir, (5) southeast of Kenaston, (6) Watrous, (7) Meskanaw, (8) east of Yellow Creek, and (9) west of Simpson. Several of these locations fall within the known range of this mammal as reported by Nero 23456 . They are, however, new localities within this range. The occurrence at

\footnotetext{
*Provincial Museum of Alberta,

Edmonton, Alberta.
}

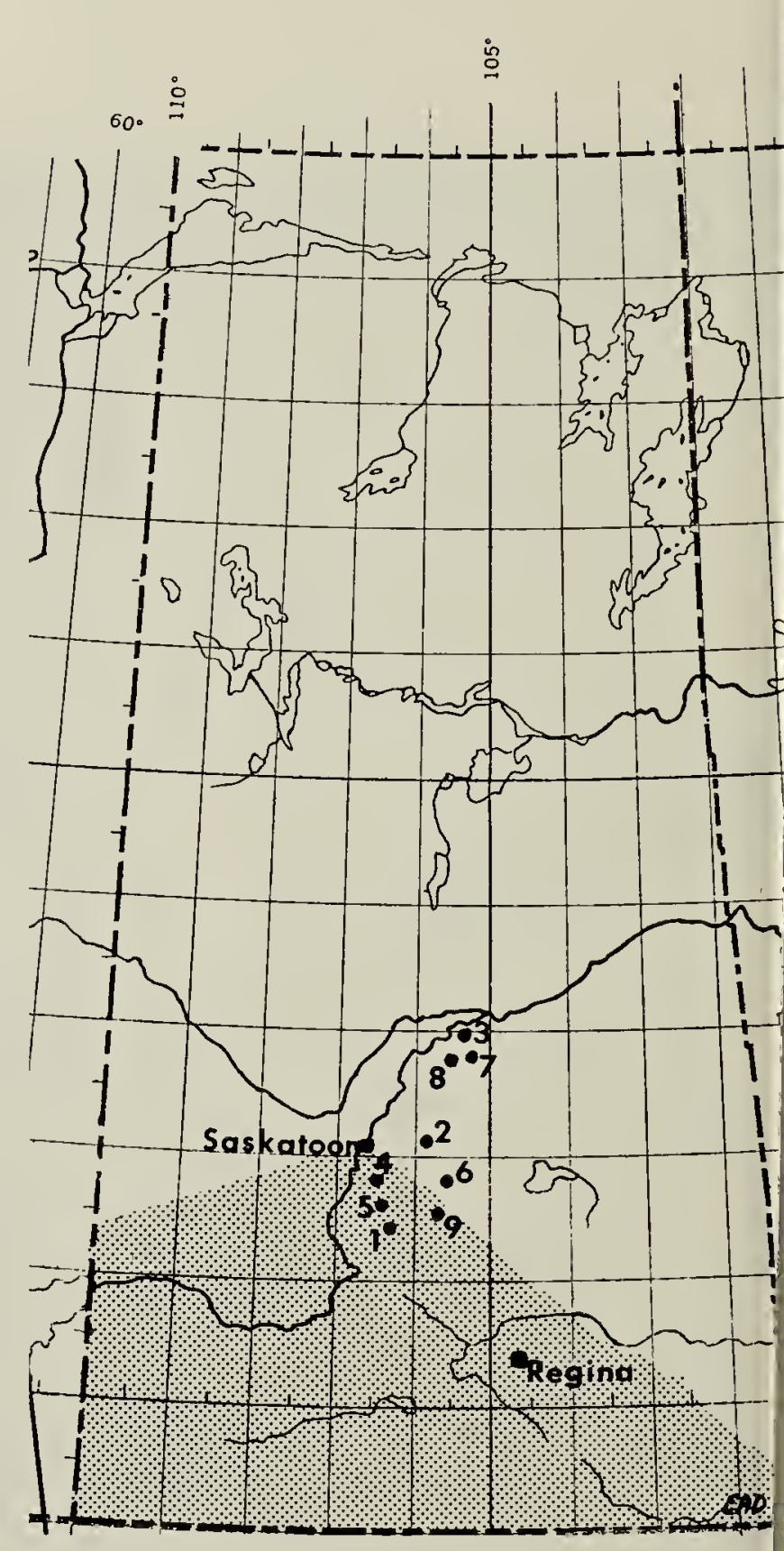

Range of Olive-backed Pocket Mouse w additional records.

Birch Hills, Meskanaw, and Yell Creek is unexpected and constitute: range extension of approximately miles northeast of the known ran: The occurrence at Birch Hills a marks the northernmost record of a heteromyid rodent. 
